\title{
Planejamento Educacional Individulizado na Classe Hospitalar: apontamentos de professores em um curso de formação reflexiva colaborativa
}

\author{
Adriana Garcia Gonçalves ${ }^{1}$ \\ Aline Ferreira Rodrigues Pacco ${ }^{2}$
}

\begin{abstract}
RESUMO
A partir da necessidade de formação frente ao atendimento escolar hospitalar, bem como, a importância do planejamento frente a esse serviço, o presente estudo objetivou analisar os estudos de casos e Planejamentos Educacionais Individualizados (PEIs) desenvolvidos pelos 22 participantes de um curso de formação reflexiva colaborativa. A pesquisa se constitui em caráter colaborativo com abordagem qualitativa. A pesquisa foi desenvolvida em uma diretoria de ensino, onde ocorreu um curso de formação continuada colaborativa, em que foram realizados cinco encontros presenciais e foram disponibilizadas cinco unidades didáticas na plataforma online do Google Classroom. Ao se pensar nas possibilidades de desenvolvimento das atividades escolares dentro do ambiente escolar hospitalar, notou-se que o PEI se constitui como uma ação favorável tanto para o aluno, como para o professor, levando em consideração que esse tipo de planejamento evidencia as principais necessidades e potencialidades do aluno, algo que é imprescindível quando o mesmo se encontra hospitalizado.
\end{abstract}

PALAVRAS-CHAVE: Educação Especial. Classe Hospitalar. Planejamento Educacional Individualizado. Formação reflexiva colaborativa.

\footnotetext{
${ }^{1}$ Doutora em Educação pela UNESP, campus de Marília. Docente do Departamento de Psicologia e do curso de PósGraduação em Educação Especial da Universidade Federal de São Carlos - UFSCar, São Paulo, Brasil. Orcid: https://orcid.org/0000-0002-5725-2001.E-mail: adrigarcia@ufscar.br.

${ }^{2}$ Doutoranda em Educação Especial pela Universidade Federal de São Carlos, UFSCar, São Carlos, São Paulo, Brasil. Orcid: https://orcid.org/0000-0002-6571-0463. E-mail: aline pacco@ hotmail.com.
} 
Individual Educational Planning in the Hospital Class: appointment of a collaborative reflective training course

\begin{abstract}
Based on the need for training in relation to hospital school attendance, as well as the importance of planning in relation to this service, this study aims to analyze the case studies and Individual Educational Plans (PEIs) evaluated by the 22 participants of a training course. collaborative reflective. The research is described in a collaborative character with a qualitative approach. A survey was conducted in a teaching director, where a collaborative continuing education course took place, in which five face-to-face meetings were held and five teaching units were made available on the Google Classroom online platform. When you think about the possibilities of developing school activities within the hospital school environment, you do not know what PEI is and how an action is so beneficial for the student, as for the teacher, taking into account that this type of planning evidence is main. and the student's potential, something that is essential when he is hospitalized.
\end{abstract}

KEYWORDS: Special education. Hospital Class. Individualized Educational Planning. Collaborative reflective training.

Planificación educativa individual en la clase hospitalaria: nombramiento de un curso colaborativo de formación reflexiva

\title{
RESUMEN
}

Basado en la necesidad de capacitación en relación con la asistencia a la escuela del hospital, así como la importancia de la planificación en relación con este servicio, el presente estudio tuvo como objetivo analizar los estudios de caso y los Planes Educativos Individualizados (PEI) desarrollados por los 22 participantes de un curso de capacitación reflexiva colaborativo La investigación constituye un carácter colaborativo con un enfoque cualitativo. La investigación se desarrolló en un tablero de enseñanza, donde se llevó a cabo un curso colaborativo de educación continua, en el que se llevaron a cabo cinco reuniones presenciales y se pusieron a disposición cinco unidades de enseñanza en la plataforma en línea Google Classroom. Al pensar en las posibilidades de desarrollar actividades escolares dentro del entorno escolar del hospital, se observó que el PEI constituye una acción favorable tanto para 
el alumno como para el profesor, teniendo en cuenta que este tipo de planificación resalta las principales necesidades. y el potencial del estudiante, algo que es esencial cuando está hospitalizado.

PALABRAS CLAVE: Educación Especial. Clase hospitalaria. Planificación educativa individualizada. Entrenamiento reflexivo colaborativo.

$$
* * *
$$

\section{Introdução}

O planejamento dentro do ambiente escolar hospitalar é algo muito complexo. Se trata de um grande desafio, considerando que o mesmo deve estar pautado nas especificidades que o hospital apresenta, nas principais necessidades do aluno, sua idade e ano escolar, bem como o currículo expresso para a Educação Básica. Fonseca (2008) coloca que o professor que atua nesse serviço deve considerar os acometimentos na saúde dos alunos, a rotina dentro do ambiente hospitalar e os procedimentos terapêuticos, para a realização do seu planejamento.

Se tratando do professor que atua em ambiente escolar hospitalar, evidencia-se que este tem que estar atento às especificidades que o hospital apresenta, considerando que:

A atividade docente em ambiente hospitalar tem características diferenciadas daquelas que se manifestam em instituições escolares. Isso ocorre tanto em razão das condições de saúde do aluno, que se encontra no lugar de paciente, como pelas características do espaço onde são desenvolvidas as atividades pedagógicas (REIS, 2017, p.21)

Desse modo, ser docente no ambiente hospitalar representa estar disposto a adequar-se às especificidades deste espaço, ou seja, estar em constante mudança, adaptando-se às condições dos diferentes alunos/pacientes e compreendendo a complexidade da docência nesse lócus específico.

Fomenta-se que as formações específicas para atuar dentro do ambiente escolar hospitalar ainda são escassas e, dessa maneira, a identidade 
do professor de classe hospitalar, muitas vezes, se constitui durante sua atuação cotidiana (REIS, 2017).

O docente que lida com um público cercado de especificidades, demanda ter uma rede de possibilidades para obter conhecimentos que atendam às necessidades de seu alunado.

Para Lima (2015), a formação do professor de educação especial e também do professor de classe hospitalar é um dos grandes desafios para a efetivação de uma educação de qualidade para todos. É preciso lidar com o despreparo:

[...] dos professores (formados ou em formação) para atuar na educação das crianças e adolescentes com algum tipo de deficiência e das que estão em tratamento de saúde em hospitais ou em convalescença domiciliar - uma vez que muitos professores formados ou em formação sequer conhecem a proposta de escolarização em hospitais (e em domicílio). Embora não se defenda aqui a necessidade de uma especialização do professor para atuar em classe hospitalar, reconhece-se que é preciso incluir, durante sua formação, discussões, ainda que elementares, sobre essa modalidade educacional, particularmente quando são propostos os estudos sobre educação especial (LIMA, 2015, p.39)

No cenário brasileiro depara-se com a precariedade das formações dos professores de classes hospitalares e também, a falta de estruturação das condições igualitárias de trabalho, algo que afeta diretamente a prática pedagógica (LIMA, 2015). Objetivando nortear a formação docente dos professores atuantes nas classes hospitalares e estruturar condições mais favoráveis de trabalho, se fazem necessárias “[...] políticas de formação e de condições de trabalho que devem ser alvo de fortes investimentos para que o trabalho docente possa ascender a uma condição mais digna de trabalho" (HYPOLITO, 2015, p. 517).

A partir da necessidade de formação frente ao atendimento escolar hospitalar, bem como, a importância do planejamento frente a esse serviço, o presente estudo objetivou analisar os estudos de casos e Planejamentos Educacionais Individualizados (PEIs) desenvolvidos pelos participantes de um curso de formação reflexiva colaborativa. 


\section{Método}

A presente pesquisa se constituiu em caráter colaborativo com abordagem qualitativa, em que participaram da pesquisa 22 participantes, sendo três professoras que lecionavam em classes hospitalares, 14 professoras de Educação Especial, três professoras de apoio (acompanhavam em classe comum os alunos PAEE) e duas coordenadoras da Educação Especial.

Cabe destacar que, a proposta inicial era a de realizar o curso juntamente com os professores das classes hospitalares, mas, no entanto, por se tratar de uma pesquisa colaborativa, em que as ações foram realizadas totalmente em parceria com a diretoria de ensino em questão, as coordenadoras apresentaram a necessidade de formação para os demais professores da Educação Especial. Desta forma, a presente formação continuada foi aberta para todos os professores de Educação Especial que tivessem interesse em se inscrever para realizar o curso de formação.

Considera-se que a pesquisa se constitui no âmbito da colaboração, tendo em vista que, desde o processo de construção do curso, houve a parceria com as coordenadoras do núcleo pedagógico de Educação Especial, bem como, no decorrer do curso, os conteúdos abordados foram elencados em parceria com os participantes, de acordo com as necessidades dos mesmos.

A pesquisa foi desenvolvida em uma diretoria de ensino, localizada em uma cidade do interior paulista, onde ocorreu um curso de formação continuada colaborativa, em que foram realizados cinco encontros presenciais e foram disponibilizadas cinco unidades didáticas na plataforma online do Google Classroom.

Todos os encontros foram gravados e posteriormente houve a transcrição dos relatos de fala dos participantes.

O material analisado nesse estudo, se faz as respostas dos participantes no fórum de discussão no ambiente virtual que tinha como foco o planejamento para alunos hospitalizados, em que a questão era: "Na sua opinião, qual a forma mais adequada de realizar um planejamento para alunos que estejam hospitalizados?, 
os relatos de fala dos encontros presenciais sobre a temática do PEI. A partir dessa análise, observou-se a demanada levantada pelos participantes sobre o planejamento educacional dentro do ambiente hospitalar, dessa forma, foram construídos em grupos seis estudos de casos e seus respectivos planejamentos. Os grupos foram definidos pelos próprios participantes.

A pesquisadora disponibilizou um exemplo de estudo de caso, que foi construído por ela e dois exemplos de planejamentos, modelos que foram retirados da internet. Apesar do sugerido, cada grupo poderia realizar a construção do material da maneira que acreditasse ser a mais adequada, criando um caso fictício ou utilizando para tal suas próprias experiências profissionais dentro do hospital.

Após a construção dos estudos de casos e seus respectivos planejamentos, estes foram disponibilizados no ambiente virtual, em que foram abertos fóruns de discussão, para que os participantes pudessem fornecer opiniões para completametação dos planejamentos.

Por último houve um encontro presencial, objetivando a complementação dos casos e seus respectivos planejamentos, buscando explicitar quaisquer dúvidos entre os grupos.

A partir da análise dos dados de modo qualitativo, foi elaborado um sistema de categorização e agrupamento dos relatos de fala e respostas dos participantes nas atividades.

Destaca-se que, o presente estudo foi aprovado no Comitê de Ética de Pesquisa em Seres Humanos da Universidade Federal de São Carlos (UFSCar), sob o número do CAEE 81168617.8.0000.5504.

\section{Resultados e Discussões}

\section{Respostas obtidas dos participantes no fórum de discussão sobre planejamento}

A partir da questão problematizados sobre planejamento, obteve-se 19 respostas para essa questão e, de forma geral, os participantes (P2, P8, P9, P11, P12, P17) apontaram que o planejamento deve ser pensado de forma 
individual, considerando as necessidades de cada aluno, o tempo de internação e partindo da ludicidade, algo que pode ser exemplificado na resposta a seguir:

Partindo de uma sondagem individual, já que cada aluno é único dentro de suas especificidades, trazendo consigo sua bagagem de vida. Após uma noção de quem é esse aluno, as atividades poderão ser organizadas de acordo com a realidade do ambiente hospitalar (espaço, tempo etc.) e com as necessidades do aluno para aquele momento ou situação em sua vida ( atividades mais lúdicas, de reforço escolar, momentos em grupo etc.). O tempo dentro deste planejamento é muito relevante, pois o atendimento pode durar apenas um dia ou até meses, por isso o professor especializado precisa aprender a ter "cartas na manga" diante das mais variadas situações (jogos pedagógicos, desenhos, pinturas, passatempos, livros etc.). $O$ que vale neste serviço é tranquilizar $e$ proporcionar um ambiente confiável, onde o aluno se sinta capaz e seguro (P12, ambiente virtual).

A ação de planejar sugere uma reflexão frente às decisões que se deve tomar sobre as práticas empregadas (AIRES, 2009), principalmente no que se refere às necessidades individuais de cada aluno.

Lima e Lugli (2020) reforçam a importância de se respeitar a individualidade e a afetividade de cada aluno, considerando que tais aspectos são fundamentais para a estruturação do ambeinete educacional hospitalar.

Além do mais, é de de extrema importância que o professor programe o seu horário de trabalho para planejar suas ações frente aos alunos hospitalizados e organizar o material a ser usado (FONSECA, 2008).

Nota-se que os participantes (P9, P11, P13, P15, C2) também apontaram que o planejamento deve ser algo contínuo e que deve se levar em consideração a condição do aluno, por meio da escuta pedagógica, como visto na resposta a seguir:

Deve estar pautado em ajudar a proporcionar o bem-estar nos alunos que se encontram internados, ajudá-los a sentirse interligados com o mundo exterior ao hospital. É importante que a "escuta pedagógica" que tantos autores citam em seus textos esteja presente, para que os professores tenham noção de como o aluno está emocionalmente e 
psicologicamente. Deve "sentir" seus alunos e direcionar as atividades de acordo com o contexto que encontrar no dia, as vezes é necessário utilizar apenas o lúdico ou então combinalos com atividades escolares (P13, ambiente virtual).

A escuta pedagógica se constitui como um aspecto fundamental na atuação docente dentro do ambiente escolar hospitalar, pois possibilita ao professor o olhar para seu aluno de forma integral, percebendo suas necessidades (ANDRADE, 2013).

Ceccim e Carvalho (1997) apontam que a escuta pedagógica:

[...] provém da psicanálise e diferencia-se da audição. Enquanto a audição se refere à apreensão/compreensão de vozes e sons audíveis, a escuta se refere à apreensão/compreensão de expectativas e sentidos, ouvindo através das palavras as lacunas do que é dito e os silêncios, ouvindo expressões e gestos, condutas e posturas. A escuta não se limita ao campo da fala ou do falado, busca perscrutar os mundos interpessoais que constituem nossa subjetividade para cartografar o movimento das forças de vida que engendram nossa singularidade (CECCIM; CARVALHO, 1997, p. 31)

Assim, a escuta pedagógica permite que o professor conheça seu aluno e os seus principais desafios, possibilitando que o docente ofereça ajuda em um momento tão complexo como é a hospitalização.

Para além, o professor deve considerar em seu planejamento que seus alunos, mesmo em estado de hospitalização, não deixam de serem crianças ou adolescentes para se tornarem pacientes, não deixam de serem seres movidos por emoções, pelo movimento e pela curiosidade (FONTES, 2015).

Uma questão que emergiu com frequência nas respostas dos participantes (P8, P14, P15, P17, P19, C1, C2) foi a necessidade de se trabalhar conteúdos do currículo da escola de origem do aluno, enfatizando a importância de se manter o contato com essa escola a qual ele pertence, realizando as adaptações curriculares necessárias, como visto nas respostas a seguir: 
O planejamento, o currículo e os conteúdos da classe hospitalar tanto para os alunos/pacientes internados por curto ou longo prazo devem ser os mesmos praticados na escola de origem dos mesmos, o modo de conduzir é que serão constantemente adaptados às necessidades que possam surgir no cotidiano da classe e/ou ambulatórios e/ou leito e/ou brinquedoteca, as estratégias devem ser através de abordagem lúdica com recursos adaptáveis e ser revisto diariamente, pois o tempo do aluno/paciente é muito diferente (P15, ambiente virtual).

[...] ter contato com a escola de origem do aluno dando continuidade à vida acadêmica do estudante (P8, ambiente virtual).

Para além dos conteúdos trabalhados na escola de origem do aluno, destaca-se a importância de se planejar focalizando as necessidades dos alunos, se pautar em atividades adaptadas, com conteúdo selecionado e utilizando significados mais concretos, em atividades lúdicas e criativas, e proporcionar interações entre os alunos (MORGADO, 2015).

Uma participante citou a necessidade de se realizar um Plano de Atendimento Individualizado (PAI), que pode ser considerado equivalente ao Planejamento Educacional Individualizado (PEI), que foi trabalhado posteriormente no curso de formação, algo que pode ser visto no excerto a seguir:

Os alunos que estarão hospitalizados em um período de tempo
maior, deveria fazer o PAI (Plano de atendimento
individualizado, no qual deveria constar os objetivos da
criança, idade, (o que a criançajá sabe fazer, quais são os seus
déficits) através de uma avaliação e depois estabelecer os
objetivos dentro de cada área (motora, comunicação
pedagógica...), estabelecer programas de ensino (como ensinar)
e depois através de registro medir se este aluno está
aprendendo ou não (P2, ambiente virtual).

A Resolução n.72, de 22 de dezembro de 2016 (SÃO PAULO, 2016), que norteia o trabalho das classes hospitalares no estado de São Paulo, coloca que os professores atuantes nesse espaço devem realizar o Plano de Atendimento Individualizado (PAI), e traz em anexo um modelo a ser seguido. No entanto, percebeu-se que a maioria dos professores não utiliza tal modelo. 


\section{Resultado dos estudos de caso e planejamentos elaborados pelos participantes do estudo}

No quadro a seguir, pode-se verificar uma breve síntese dos trabalhos desenvolvidos.

Quadro 1: Síntese dos Estudos de Casos e Planejamentos

\begin{tabular}{|c|c|c|c|c|}
\hline Grupo & $\begin{array}{l}\text { Informações } \\
\text { básicas do aluno }\end{array}$ & $\begin{array}{c}\text { Tempo para } \\
\text { execução do } \\
\text { planejamento }\end{array}$ & $\begin{array}{l}\text { Principais } \\
\text { ações }\end{array}$ & Avaliação \\
\hline 1 & $\begin{array}{l}\text { Idade: } 7 \text { anos } \\
\text { Diagnóstico: } \\
\text { Cirúrgico, operação no } \\
\text { joelho, dificuldade de } \\
\text { locomoção. } \\
\text { Tempo de } \\
\text { internação: } 5 \text { dias } \\
\text { Série: } 1 \text { ano do } \\
\text { Ensino Fundamental I } \\
\text { Principais } \\
\text { Interesses: Ama } \\
\text { ouvir história da } \\
\text { literatura infantil, } \\
\text { principalmente dos } \\
\text { "Três Porquinhos" } \\
\text { Principais } \\
\text { Potencialidades e } \\
\text { Dificuldades: Fase } \\
\text { Pré-Silábica, não } \\
\text { gosta muito de } \\
\text { matemática. }\end{array}$ & Curto prazo & $\begin{array}{l}\text { Contação de } \\
\text { história dos Três } \\
\text { Porquinhos, } \\
\text { manuseio } \\
\text { alfabeto móvel, } \\
\text { escrita do nome } \\
\text { dos personagens } \\
\text { com mediação, } \\
\text { contação de } \\
\text { história pelo } \\
\text { aluno com } \\
\text { fantoches, } \\
\text { pintura de } \\
\text { desenho. }\end{array}$ & $\begin{array}{l}\text { "Atendimento } \\
\text { tranquilo, onde } \\
\text { interagiu bem } \\
\text { com o } \\
\text { aluno/paciente e } \\
\text { sua família. Ele } \\
\text { adorou as } \\
\text { atividades e ficava } \\
\text { querendo mais } \\
\text { quando as } \\
\text { finalizava. Mesmo } \\
\text { me dizendo que } \\
\text { não gostava muito } \\
\text { de matemática, } \\
\text { sempre o } \\
\text { questionava sobre } \\
\text { a quantidade de } \\
\text { personagens da } \\
\text { cena e a } \\
\text { quantidade de } \\
\text { letras que } \\
\text { utilizava para } \\
\text { escrever as } \\
\text { palavras" }\end{array}$ \\
\hline 2 & $\begin{array}{l}\text { Idade: } 6 \text { anos } \\
\text { Diagnóstico: } \\
\text { Síndrome de Hoffman } \\
\text { (paciente acamado, } \\
\text { traqueostomia, } \\
\text { alimentação por } \\
\text { sonda, uso de fralda, } \\
\text { só responde através de } \\
\text { movimentos oculares) } \\
\text { Série: } 1^{\circ} \text { ano do ciclo } \\
\text { I/ Está afastado da } \\
\text { escola, mora no } \\
\text { hospital. } \\
\text { Principais } \\
\text { interesses: Língua } \\
\text { portuguesa, músicas, }\end{array}$ & Não informou & $\begin{array}{l}\text { Uso do alfabeto } \\
\text { móvel. } \\
\text { Leitura de textos } \\
\text { pela professora } \\
\text { Prancha de } \\
\text { comunicação } \\
\text { alternativa } \\
\text { Estimativa de } \\
\text { atendimento: } 30 \\
\text { minutos diários. }\end{array}$ & $\begin{array}{l}\text { Contínua, com } \\
\text { relatório final a } \\
\text { cada bimestre, } \\
\text { entregue na } \\
\text { escola em que o } \\
\text { aluno está } \\
\text { matriculado. }\end{array}$ \\
\hline
\end{tabular}




\begin{tabular}{|c|c|c|c|c|}
\hline & $\begin{array}{l}\text { bola, filmes animados } \\
\text { (Chaves). } \\
\text { Principais } \\
\text { Potencialidades e } \\
\text { Dificuldades: } \\
\text { Intelecto preservado, } \\
\text { sensibilidade } \\
\text { preservada, } \\
\text { parcialmente } \\
\text { demonstra interesse } \\
\text { nas atividades, não } \\
\text { consegue sentar por } \\
\text { falta de controle do } \\
\text { tronco e apenas } \\
\text { consegue se comunicar } \\
\text { visualmente. }\end{array}$ & & & \\
\hline 3 & $\begin{array}{l}\text { Idade: } 17 \text { anos } \\
\text { Série: } 3^{\circ} \text { ano do } \\
\text { ensino médio } \\
\text { Diagnóstico: } \\
\text { Deficiência Auditiva } \\
\text { (Surdez Profunda), } \\
\text { recuperação de uma } \\
\text { cirurgia de apêndice } \\
\text { com complicações no } \\
\text { pós operatório. } \\
\text { Tempo de } \\
\text { afastamento: } 1 \text { mês e } \\
9 \text { dias (devido ao mal- } \\
\text { estar constante) } \\
\text { Interesses: Tem } \\
\text { interesse na disciplina } \\
\text { de matemática em } \\
\text { resolver operações, } \\
\text { ainda tem facilidade e } \\
\text { habilidade para } \\
\text { desenhar, assim gosta } \\
\text { muito de desenhos de } \\
\text { Mangá. } \\
\text { Domina a Língua de } \\
\text { Sinais Brasileira } \\
\text { (LIBRAS) e desenho. } \\
\text { Dificuldades: } \\
\text { Dificuldades na } \\
\text { construção de textos e } \\
\text { interpretação devido à } \\
\text { sua deficiência } \\
\text { auditiva. }\end{array}$ & Longo prazo & $\begin{array}{l}\text { Trabalhar textos } \\
\text { construtivos e } \\
\text { interpretação, } \\
\text { principalmente } \\
\text { de palavras } \\
\text { desconhecidas } \\
\text { pela aluna. Uso } \\
\text { de tecnologia } \\
\text { assistiva. }\end{array}$ & $\begin{array}{l}\text { A avaliação será } \\
\text { diária, focada no } \\
\text { desenvolvimento } \\
\text { da aluna e ao } \\
\text { final será feito } \\
\text { um relatório, o } \\
\text { qual será } \\
\text { encaminhado } \\
\text { para a escola de } \\
\text { origem da aluna, } \\
\text { contando com a } \\
\text { participação da } \\
\text { equipe } \\
\text { multidsciplinar }\end{array}$ \\
\hline 4 & $\begin{array}{l}\text { Idade: } 17 \text { anos } \\
\text { Série: } 3^{\circ} \text { ano do } \\
\text { Ensino Médio } \\
\text { Diagnóstico: } \\
\text { Síndrome de Down } \\
\text { (não apontou o }\end{array}$ & Curto prazo & $\begin{array}{l}\mathbf{1}^{\mathbf{o}} \text { dia: iniciei } \\
\text { contando a } \\
\text { história, A Bela } \\
\text { e a Fera. } \\
\mathbf{2}^{\mathbf{o}} \text { dia: Trabalhei } \\
\text { linguagem, } \\
\text { escrita e leitura }\end{array}$ & $\begin{array}{l}\text { A aluna } \\
\text { interagiu com as } \\
\text { atividades } \\
\text { propostas, } \\
\text { identificou as } \\
\text { letras com } \\
\text { facilidade. }\end{array}$ \\
\hline
\end{tabular}




\begin{tabular}{|c|c|c|c|c|}
\hline & $\begin{array}{l}\text { diagnóstico que levou } \\
\text { à hospitalização) } \\
\text { Principais } \\
\text { Interesses: filme (O } \\
\text { Pequeno Príncipe), } \\
\text { Contos Infantis, } \\
\text { Língua Portuguesa. } \\
\text { Principais } \\
\text { Potencialidades e } \\
\text { dificuldades: A } \\
\text { aluna é comunicativa, } \\
\text { participativa. } \\
\text { Reconhece as letras e } \\
\text { linguagem de escrita e } \\
\text { leitura de alguns } \\
\text { gêneros textuais. } \\
\text { Demostra pouca } \\
\text { motivação para } \\
\text { realizar as atividades. }\end{array}$ & & $\begin{array}{l}\text { de alguns } \\
\text { gêneros textuais. } \\
3^{\circ} \text { dia: Levei os } \\
\text { desenhos dos } \\
\text { personagens da } \\
\text { história para } \\
\text { pintar e } \\
\text { identificar cada } \\
\text { um, escrevendo } \\
\text { seus nomes. }\end{array}$ & $\begin{array}{l}\text { Houve melhora } \\
\text { no seu tempo de } \\
\text { permanência nas } \\
\text { atividades } \\
\text { realizada, fez } \\
\text { todas atividades } \\
\text { com calma, } \\
\text { capricho e } \\
\text { envolvimento. }\end{array}$ \\
\hline 5 & $\begin{array}{l}\text { Idade: } 6 \text { anos } \\
\text { Diagnostico: } \\
\text { Insuficiência Renal } \\
\text { Crônica - afetando o } \\
\text { desenvolvimento } \\
\text { físico, intelectual, } \\
\text { emocional e social; } \\
\text { Tratamento: } \\
\text { Hemodiálise } \\
\text { Série: } 1^{\circ} \text { ano } \\
\text { fundamental l } \\
\text { Principais } \\
\text { interesses: Jogos } \\
\text { (Many Craft), } \\
\text { matemática e Cantar. } \\
\text { Principais } \\
\text { Potencialidades e } \\
\text { dificuldades: Pré- } \\
\text { Silábico não gosta de } \\
\text { escrever e nem que } \\
\text { fale em fazer } \\
\text { atividades de escrita, } \\
\text { ainda escreve algumas } \\
\text { letras e números } \\
\text { espelhados, está em } \\
\text { processo de } \\
\text { alfabetização. }\end{array}$ & Longo prazo & $\begin{array}{l}\text { Ganhar a } \\
\text { confiança do } \\
\text { aluno, adaptar } \\
\text { as atividades } \\
\text { com o interesse } \\
\text { do aluno, criar } \\
\text { maneira para o } \\
\text { aluno perceber } \\
\text { que precisa } \\
\text { conhecer as } \\
\text { letras e saber } \\
\text { escrever para } \\
\text { conseguir } \\
\text { entender e jogar } \\
\text { melhor, fazer } \\
\text { atividades de } \\
\text { matemática com } \\
\text { o tema preferido } \\
\text { dele e mostrar } \\
\text { que a } \\
\text { matemática } \\
\text { assim como a } \\
\text { Língua } \\
\text { Portuguesa está } \\
\text { inserido no jogo. }\end{array}$ & $\begin{array}{l}\text { O atendimento } \\
\text { inicial foi } \\
\text { tranquilo, o } \\
\text { aluno/paciente } \\
\text { ficou motivado } \\
\text { ao ver que pode } \\
\text { estudar e } \\
\text { aprender com o } \\
\text { tema do jogo que } \\
\text { tanto gosta. Irei } \\
\text { fazer uma } \\
\text { avaliação e } \\
\text { relatório e } \\
\text { entregarei na } \\
\text { escola em que o } \\
\text { aluno está } \\
\text { matriculado no } \\
\text { final de cada } \\
\text { bimestre. }\end{array}$ \\
\hline 6 & $\begin{array}{l}\text { Idade: } 15 \text { anos } \\
\text { Diagnóstico: } \\
\text { tratamento devido ao } \\
\text { uso abusivo de bebida } \\
\text { alcoólica e } \\
\text { entorpecente ilícito } \\
\text { Principais } \\
\text { interesses: música e } \\
\text { desenho }\end{array}$ & Longo prazo & $\begin{array}{l}\text {-Aulas diárias } \\
\text { em sala própria } \\
\text { dentro da ala } \\
\text { hospitalar com } \\
\text { duração de } 2 \\
\text { horas } \\
\text {-Sondagem de } \\
\text { interesse }\end{array}$ & $\begin{array}{l}\text { Levar em conta o } \\
\text { estado de saúde } \\
\text { e emocional, } \\
\text { participação, } \\
\text { interesse, } \\
\text { dificuldades. } \\
\text { Sendo contínua e } \\
\text { mediando em }\end{array}$ \\
\hline
\end{tabular}




\begin{tabular}{|l|l|l|l|}
\hline $\begin{array}{l}\text { Principais } \\
\text { dificuldades: está }\end{array}$ & & -Escolha de & situações \\
silábica alfabética, & música de boa & necessárias. \\
realiza leitura de & qualidade e & \\
forma truncada, pouco & & discussão sobre & \\
inteligível, retira & sua temática & \\
informação explícita & -Escrita & \\
de texto curto com & espontânea de & \\
auxílio. Não realiza & lista de palavras & \\
cálculos e conhece & sobre a música & \\
números de 1 a 20 & -Exposição em & \\
Período de & sala do desenho & \\
internação: 3 meses & & e da atividade & \\
\hline
\end{tabular}

Fonte: Elaboração própria.

No decorrer da elaboração dos PEIs nesse estudo, destaca-se que houve a apresentação de modelos para os participantes, no entanto, cada grupo construiu seu planejmaneto com as informações que consideraram relevantes, demosntrando assim, que não há um modelo definido, devido a especificidade que esse serviço apresenta.

No quadro a seguir, pode-se verificar os comentários dos participantes na plataforma digital e também na aula presencial. 
Quadro 2: Comentários dos participantes frente aos Estudos de Casos e

\section{Planejamentos}

\begin{tabular}{|c|c|c|}
\hline Grupo & $\begin{array}{c}\text { Comentários na Plataforma } \\
\text { online }\end{array}$ & $\begin{array}{c}\text { Comentários na aula } \\
\text { presencial }\end{array}$ \\
\hline 1 & $\begin{array}{l}\text {-Bom uso da temática escolhida, } \\
\text { levando em consideração o } \\
\text { interesse do aluno e a idade/ano } \\
\text { escolar; } \\
\text {-Possível adequação do tempo da } \\
\text { realização das atividades, devido } \\
\text { aos procedimentos médicos; } \\
\text {-Inserção de uma avaliação } \\
\text { destinada à escola de origem do } \\
\text { aluno. }\end{array}$ & $\begin{array}{l}\text {-Acréscimo do envio das atividades } \\
\text { desenvolvidas pelo aluno para a } \\
\text { sua escola de origem; } \\
\text {-Realização de atividades que, de } \\
\text { forma implícita, trabalhavam a } \\
\text { disciplina de matemática, que era } \\
\text { algo que o aluno apresentava } \\
\text { dificuldades e não demonstrava } \\
\text { interesse. }\end{array}$ \\
\hline 2 & $\begin{array}{l}\text {-Inserção do uso de tecnologia } \\
\text { assistiva, como por exemplo } \\
\text { softwares de reconhecimento de } \\
\text { voz e visão, acionadores e } \\
\text { pranchas de comunicação } \\
\text { alternativa. }\end{array}$ & $\begin{array}{l}\text {-Obtenção de maiores informações } \\
\text { sobre o diagnóstico do aluno; } \\
\text {-Envolvimento da família, } \\
\text { buscando implementar um meio de } \\
\text { comunicação para/com o aluno. }\end{array}$ \\
\hline 3 & $\begin{array}{l}\text {-Planejamento completo, } \\
\text { pensando em aspectos do futuro } \\
\text { do aluno, considerando a Libras } \\
\text { como sua primeira língua, bem } \\
\text { como o uso de dispositivos } \\
\text { tecnológicos. }\end{array}$ & $\begin{array}{l}\text {-Planejamento completo, } \\
\text { evidenciando a importância da } \\
\text { participação da equipe } \\
\text { multidisciplinar. }\end{array}$ \\
\hline 4 & $\begin{array}{l}\text {-Inserção do tipo de patologia que } \\
\text { gerou a internação; } \\
\text {-Possível uso de tecnologias, } \\
\text { principalmente para despertar o } \\
\text { interesse da aluna; } \\
\text {-Contato com a escola de origem, } \\
\text { objetivando conhecer os conteúdos } \\
\text { que estão sendo trabalhados e } \\
\text { escolha de outros materiais para } \\
\text { leitura, considerando a idade/ano } \\
\text { escolar que a aluna está } \\
\text { matriculada. }\end{array}$ & $\begin{array}{l}\text {-Acréscimo de informações sobre o } \\
\text { estado do aluno, como por exemplo, } \\
\text { se ele se encontra acamado ou não; } \\
\text {-Infantilização de alunos } \\
\text { adolescentes com deficiência; } \\
\text {-Importância de colocar no } \\
\text { planejamento o envolvimento da } \\
\text { família. }\end{array}$ \\
\hline 5 & $\begin{array}{l}\text {-Bom uso do lúdico; } \\
\text {-Inserção da descrição dos jogos } \\
\text { utilizados, do tempo em que as } \\
\text { atividades serão realizadas e } \\
\text { quais os recursos utilizados para o } \\
\text { estabelecimento da relação de } \\
\text { confiança entre o professor e o } \\
\text { aluno. }\end{array}$ & $\begin{array}{l}\text {-Importância de se descrever as } \\
\text { ações que seriam realizadas para } \\
\text { estabelecer uma relação de } \\
\text { confiança com o aluno. }\end{array}$ \\
\hline 6 & $\begin{array}{l}\text {-Bom uso de tecnologias; } \\
\text {-Inserção de práticas envolvendo o } \\
\text { artesanato e a escuta pedagógica. }\end{array}$ & $\begin{array}{l}\text {-Inserção de atividades de vida } \\
\text { diária. }\end{array}$ \\
\hline
\end{tabular}

Fonte: Elaboração própria. 
No estudo de caso 1 foram propostas atividades de contação de história, desenho e escrita para um aluno de sete anos, em estado de pós-operatório, em um período de internação de cinco dias.

A partir dos comentários dos participantes sobre o estudo de caso 1, destaca-se a importância do contato com a escola de origem do aluno hospitalizado, objetivando auxiliar no processo de aprendizagem durante o período de hospitalização, bem como, ao seu retorno a escola regular. Pacco (2017) ao realizar uma pesquisa com professores de classes hospitalares em âmbito nacional, destacou que a maioria dos professores relatou a importância de se estabelecer esse contato com a escola de origem do aluno hospitalizado, para obter um bom retorno a vida social e escolar.

Dessa forma, reforça-se a importância de se estabelecer um trabalho colaborativo entre o professor da classe hospitalar e o professor da escola de origem, principalmente na elaboração do PEI.

No estudo de caso 2 foram propostas atividades de contação de história, escrita e desenvolvimento da comunicação, para um aluno de seis anos, que reside no hospital.

Levando em consideração, que este caso trouxe uma proposta de atendimento para um aluno que reside no hospital, aponta-se para a importância da classe hospitalar, considerando que a escola se adentra ao hospital, ressignificando esse espaço.

No estudo de caso 3 foram propostas atividades de interpretação de texto, por meio do uso de tecnologia assistiva para um aluno de 17 anos com surdez, que ficará no hospital por cerca de um mês.

Cabe destacar que o planejamento do grupo três foi o único que apontou ações junto à família e outros profissionais da saúde e mencionou o contato com a escola de origem do aluno.

É importante que, durante todo o processo de hospitalização, seja estabelecida uma ligação entre o professor da classe hospitalar, a família e a escola de origem do aluno, objetivando desenvolver o aprendizado, além de minimizar os efeitos negativos do processo de internação (ORTIZ; FREITAS, 2005). 
No estudo de caso 4 foram propostas atividades de contação de história, desenho e escrita para um aluno de 17 anos com Síndrome de Down.

Considerando que no planejamento do grupo 4, foi apontado a infantilização da aluna com deficiência, se constitui importante destacar, que ainda a infantilização de adolescentes com deficiência é muito recorrente. Meletti (2006) aponta que há uma ênfase em conteúdos curriculares da Educação Infantil para alunos com deficiência da faixa etária de sete a 16 anos, tendo por base o nível cognitivo e não se voltando para práticas direcionadas aos conteúdos condizentes com a idade cronológica dos alunos.No estudo de caso 5, foram propostas atividades lúdicas, buscando o ensino de matemática e português para um aluno de seis anos com diagnóstico de insuficiência renal crônica.

A partir dos comentários frente ao caso 5, destca-se que os objetivos e as estratégias de ensino, devem estar descritos no planejamento, desta forma, a elaboração do PEI, se torna um meio de estabelecer e sistematizar os objetivos propostos e as ações que serão realizadas para atingir tais objetivos,

No estudo de caso 6 foram propostas atividades de interpretação de músicas e desenho para um aluno de 15 anos de idade em tratamento devido ao uso abusivo de bebida alcoólica e entorpecente ilícito.

Aponta-se para a importância do atendimento ao escolar hospitalizado em hospitais ou setores que atendem especificamente pacientes do sistema de saúde mental, principalmente adolescentes em recuperação por dependência de drogas e/ou álcool, considerando que independente de qualquer condição, a criança ou adolescente tem direito á educação.

Como pode ser visto ao longo de todo o estudo, o atendimento educacional hospitalar é um serviço que possibilita a existência de distintas realidades, assim, discute-se a importância da formação dos professores para atuar nesse espaço, considerando que ser docente no ambiente hospitalar representa estar disposto a adequar-se às especificidades deste ambiente, ou seja, estar em constante mudança, adaptando-se às condições dos diferentes alunos/pacientes e compreendendo a complexidade da docência nesse lócus específico. 
De forma geral, percebe-se que todos os grupos desenvolveram os estudos de casos e seus respectivos planejamentos educacionais individualizados, trabalhando de forma colaborativa, havendo o apoio mutuo entre ios participantes, bem como, a discussão coletiva dos casos.

Destaca-se que principalmente o grupo três, desenvolveu um PEI de forma mais completa, considerando que foram elaborados materiais que se caracterizam na descrição adequada de um planejamento, proposto por Tannús- Valadão (2013):

O PEI deve ser um plano escrito, uma espécie de contrato, que descreve o programa educacional em termos de serviços demandados por um estudante em particular, tomando como base uma avaliação aprofundada dos pontos fortes e suas necessidades que afetam a habilidade dele de aprender e para demonstrar a aprendizagem. Ele é um registro das acomodações individualizadas que são necessárias para ajudar o estudante a alcançar expectativas de aprendizagem, configurando-se como um documento norteador do trabalho educacional que identifica como as expectativas de aprendizagem para todos podem ser alteradas, levando-se em consideração as necessidades do aluno e o currículo padrão, bem como a identificação de metas alternativas nas áreas de programas, caso seja necessário (TANNÚS- VALADÃO, 2013, p.55).

O Planejamento Educacional Individualizado é um método institucionalizado por lei em diversos países desenvolvidos, como os Estados Unidos, França e Itália, e um meio de garantir resultados positivos frente ao processo de escolarização de alunos com deficiência (TANNÚS-VALADÃO, 2013). No entanto, para Reis (2017), esse planejamento vem sendo utilizado por professores das classes hospitalares, considerando que o aluno que se encontra em estado de hospitalização apresenta necessidades especiais, ainda que por um determinado período de tempo. Desta forma, o PEI se torna um importante recurso no ambiente escolar hospitalar.

Em alguns países, o PEI dentro do ambiente escolar hospitalar, já é uma estratégia educacional comum, sendo regulamentado pelo Ministério da Educação, como por exemplo, na Colômbia. Segundo o documento Orientaciones para la implementación del apoyo académico especial y apoyo 
emocional a niñas, niños y jóvenes en condición de enfermedad, os professores atuantes nas classes hospitalares devem elaborar e adequar o PEI para os alunos hospitalizados, de acordo com suas necessidades (COLÔMBIA, 2015).

\section{Conclusão}

Pode-se concluir que, ao se pensar nas possibilidades de desenvolvimento das atividades escolares dentro do ambiente escolar hospitalar, notou-se que o Planejamento Educacional Especializado (PEI) se constitui como uma ação favorável tanto para o aluno, como para o professor, levando em consideração que esse tipo de planejamento evidencia as principais necessidades e potencialidades do aluno, algo que é imprescindível quando o mesmo se encontra hospitalizado.

Sugere-se que, para futuras pesquisas, que os planejamentos educacionais individualizados desenvolvidos ao longo do curso de formação, sejam aplicados na prática pelos participantes, objetivando reafirmar a importância e os benefícios educacionais que este tipo de planejamento apresenta.

Fomenta-se que a formação continuada não se concretiza como uma solução para os problemas educacionais, mas, no entanto, ela possibilita que o professor aprimore suas ações frente ao seu aluno, melhorando, assim, as condições de aprendizagem e aumentando a qualidade do ensino.

Espera-se que este trabalho tenha contribuído para com as áreas de conhecimento relacionadas à educação de modo geral e possa subsidiar discussões sobre a formação docente para a atuação no Atendimento Escolar Hospitalar, bem como, frente ao planejamento educacional individualizado nesse espaço.

\section{Referências}

AIRES, C. J. Planejamento e gestão escolar, Brasília: Universidade de Brasília, 2009. Disponível em: <http://docplayer.com.br/7538556Planejamento-e-gestao-escolar.html>. Acesso em 03 jun de 2019. 
ANDRADE, S. A. de. O pedagogo e a escuta sensível na classe hospitalar. 2013. 27f.Trabalho de Conclusão de Curso. Universidade Católica de Brasília, Brasília. 2013.Disponível em: <https://repositorio.ucb.br/jspui/handle/10869/5285> . Acesso em: 15 mar. 2018.

CECCIM, R. B.; CARVALHO, P. R. A. (Org.) Criança hospitalizada: atenção integral como escuta à vida. Porto Alegre: Editora da UFRGS, 1997.

COLÔMBIA. Ministério Nacional da Educação. Orientaciones para la implementacio $\mathrm{n}$ del apoyo acade mico especial y apoyo emocional a nin as, nin os y jo venes en condicio n de enfermedad. 2015. Disponível em: <https://docs.wixstatic.com/ugd/a2d087_71063d0d3d61425d9926c1ecf1321cb f.pdf>. Acesso em: 08 jul. 2019.

FONSECA, E.S. Atendimento escolar no ambiente hospitalar. São Paulo: Editora MEMNON. Edições Científicas. $2^{\circ}$ ed. 2008,104 p.

FONTES, R.S. A educação no hospital: um direito à vida. Revista Educação e Políticas em Debate, Uberlândia, v. 4, n.1, 2015. Disponível em: http://www.seer.ufu.br/index.php/revistaeducaopoliticas/article/view/31328. Acesso em 24 mar. 2018.

HYPOLITO, A. L. M. Trabalho docente e o novo Plano Nacional de Educação: valorização, formação e condições de trabalho. Cadernos Cedes, Campinas, v. 35, n. 97, p. 517-534, 2015. Disponível em:

http://www.scielo.br/pdf/ccedes/v35n97/1678-7110-ccedes-35-97-00517.pdf. Acesso em: 29 mai.2018.

LIMA, A. M.L; LUGLI,R.S.G. Os tempos da ação docente na classe hospoitalar. Educação, Santa Maria, v.45, p. 1-19, 2020. Disponível em: <file:///C:/Users/aline/Downloads/40241-213807-1-PB.pdf>. Acesso em: 05 abr. 2020.

LIMA, I.R.S. Políticas de educação escolar em ambientes hospitalares: em defesa da escola no hospital. Revista Educação e Políticas em Debate, Uberlândia, v. 4, n.1 , p. 29-53, 2015. Disponível em: <http://www.seer.ufu.br/index.php/revistaeducaopoliticas/article/viewFile/31 309/17043>. Acesso em: 30 mai.2018.

MELETTI, S. M. F. Educação escolar da pessoa com deficiência mental em instituições de educação especial: da política à instituição concreta. 2006, 100f. Tese de doutorado. Universidade de São Paulo, São Paulo, 2006.

MORGADO, S.Q. Atendimento pedagógico em hospital psiquiátrico infanto juvenil- HCFMUSP. Boas Práticas na perspectiva da Educação Especial Inclusiva. v.1. p.1-9, 2015. 
OBERSTEIN, S.G. Hospital-based educational services and the well-being of children with chronic illness: a self-study. College of Education, 2012. Disponível em: <http://via.library.depaul.edu/soe etd/26>. Acesso em: 26 jun.2019.

ORTIZ, L. C. M.; FREITAS, S. N. Classe hospitalar: caminhos pedagógicos entre saúde e educação. Santa Maria: UFSM, 2005.

PACCO, A.F.R. Panorama das classes hospitalares brasileiras: formação e atuação docente, organização e funcionamento. 2017. 158f. Dissertação de Mestrado. Universidade Federal de São Carlos, São Carlos, 2017.

REIS, L. V. dos. Trabalho docente e identidade nas classes hospitalares em Goiás. 2017. 130f. Dissertação de Mestrado, Universidade Federal de Goiás, Catalão, 2017. Disponível em:<https://repositorio.bc.ufg.br/tede/handle/tede/7677>. Acesso em: 15 mar. 2018.

SÃO PAULO. Resolução SE 71, de 22-12-2016. Dispõe sobre o atendimento escolar a alunos em ambiente hospitalar. Secretaria da Educação do Estado de São Paulo, 2016. Disponível em: <http://siau.edunet.sp.gov.br/ItemLise/ arquivos/71_16.HTM?Time=06/06/2019\%2020:15:49> . Acesso em: 06 jun.2019.

TÁNNUS-VALADÃO, G. Inclusão escolar e planejamento educacional individualizado: avaliação de um programa de formação continuada para educadores. 2013. 245f. Tese de Doutorado. Universidade Federal de São Carlos, São Carlos, 2013. 